\title{
Potentiation between Urecholine and gastrin extract and between Urecholine and histamine in the stimulations of Heidenhain pouches
}

\author{
IAIN E. GILLESPIE AND MORTON I. GROSSMAN \\ From the Veterans Administration Center and the Departments of \\ Medicine and Physiology, University of California, Los Angeles
}

EDITORIAL SYNOPSIS These studies clearly establish the existence of true potentiation between Urecholine and gastrin and between Urecholine and histamine in stimulating secretion both of acid and of pepsin.

It is frequently said that cholinergic activity, induced either by drugs or by vagal activity, 'potentiates' the acid secretory responses to gastrin or to histamine. The assumption that these combinations of stimuli act in a 'potentiated' rather than an 'additive' fashion is based upon the large augmentations that occur. So far as we have been able to determine, no previous study has provided data that can be analyzed in the manner required to determine whether the combined actions represent addition or potentiation (Gaddum, 1959).

Now that methods are available for the preparation of reliably potent gastrin extracts (Gregory and Tracy, 1960) the problem can be studied both with histamine and with gastrin. To provide quantitative data suitable for answering the question about potentiation, we have studied the secretion of acid and pepsin by Heidenhain pouch dogs in response to a range of dose rates of Urecholine (urethane of $\beta$-methylcholine chloride, a stable choline ester that mimics the muscarinic actions of acetylcholine), gastrin extract, and histamine, given separately and in combination.

\section{METHODS}

Observations were made on five Heidenhain pouch dogs. On each day Urecholine (bethanechol chloride, Merck, Sharp, and Dohme) was given by continuous intravenous injection at a constant rate, the rates on different days varying from 0.25 to $4 \mathrm{mg}$. per hour. After two hours of Urecholine alone, gastrin extract or histamine dihydrochloride was given by a second continuous intravenous infusion while continuing the injection of Urecholine. The dose rate of gastrin extract or of histamine was doubled every 75 minutes. Secretory rates became relatively steady within 15 minutes of starting or increasing the dose of gastrin or of histamine. For this reason the one-hour output from 15 to 75 minutes after each alteration in dose rate was taken as a measure of the response to the combination of drugs. With all but the lowest doses of Urecholine, side-effects occurred, namely, increased salivation, micturition, and defaecation. Because of the severity of these side-effects no test was done with a dose of Urecholine greater than $4 \mathrm{mg}$. per hour. Control runs of Urecholine alone, gastrin extract alone, and histamine alone, over the same dose ranges used in the combined studies, were also done on separate days.

Gastrin extracts were prepared from the mucosa of the pyloric gland area of hog stomach by a modification of the method of Gregory and Tracy (1960), as previously described (Gillespie and Grossman, 1963). A single pooled batch of gastrin extract was used for all of the studies reported here. Doses of gastrin are expressed in terms of the wet weight of mucosa represented by the extract.

Acidity of samples of gastric juice was measured by titration with $0 \cdot 1 \mathrm{~N} \mathrm{NaOH}$ with phenol red as indicator. The pepsin activity was determined by a method previously described (Grossman and Marks, 1960).

In assessing the responses to combinations of agents, the following criteria were taken to signify true potentiation, as opposed to simple additive effects.

1 If the response to the doses of the two agents given together exceeded the larger of the responses to twice the dose of each agent given separately. This criterion is, as suggested by Gaddum (1959), particularly applicable to the special case in which the agents given separately, in doses double those used when the agents are given together, produce equal responses. It is also applicable to cases in which the responses to the double doses of the agents given singly are not equal, but in this instance failure to fulfil the criterion does not signify that potentiation does not exist. Thus, it is a reliable criterion but it will tend to underestimate the frequency of instances of potentiation. 
2 If the response to the combined agents exceeded the maximal response attainable by either agent alone.

Some workers have accepted as a criterion of potentiation that the response to the two agents given together exceeded the sum of the responses to the same doses of the agents given separately. By this criterion, many agents could be proved to 'potentiate' themselves at certain dose levels. Specifically, any time one is working with that part of the dose-response curve where doubling the dose will more than double the response (and many dose-response curves have such a portion), then one could, by this criterion, erroneously conclude either that the agent was potentiating itself or that another agent that actually acts additively with the first agent was appearing to be acting by potentiation. Another criterion of potentiation that has been widely used is that a subthreshold dose of a stable choline ester produced augmentation of a response to histamine or to gastrin. With only this information one cannot determine whether such combined effects represent simple addition or true potentiation. To avoid these spurious evidences of potentiation we have adopted the criteria given above.

\section{RESULTS}

The results presented in Figs. 1 to 7 are mean values for the five dogs.

\section{ACID OUTPUTS}

URECHOLINE ALONE Figure 1 shows that with Urecholine alone the responses to the lowest doses remained reasonably constant after the first two hours of continuous infusion. When higher dose rates were used the initial high levels of response were not maintained, there being a more rapid and more profound decrease with the $2 \mathrm{mg}$. per hour dose than with $1 \mathrm{mg}$. per hour. Because of these fluctuations in acid output with time, in assessing whether potentiation was present with the combinations of agents, the acid output for the corresponding hour of the control test with Urecholine alone was used.

URECHOLINE PLUS GASTRIN It is seen from Fig. 2 that with the smaller doses of Urecholine $(0.25$ to $1 \mathrm{mg}$. per hour) responses to almost all dose rates of gastrin studied were potentiated. At a rate of $2 \mathrm{mg}$. per hour Urecholine produced less augmentation of the gastrin responses than at rates of 0.5 and $1.0 \mathrm{mg}$. per hour. With $4 \mathrm{mg}$. per hour, the largest dose of Urecholine used, outputs with the added gastrin were no greater than from that rate of Urecholine alone.

As shown in Fig. 3, the maximal acid response to the combined administration of Urecholine and gastrin extract $(7.0 \mathrm{mEq}$. per hour) was greater $(\mathrm{p}<0.01)$ than the maximum to gastrin extract alone

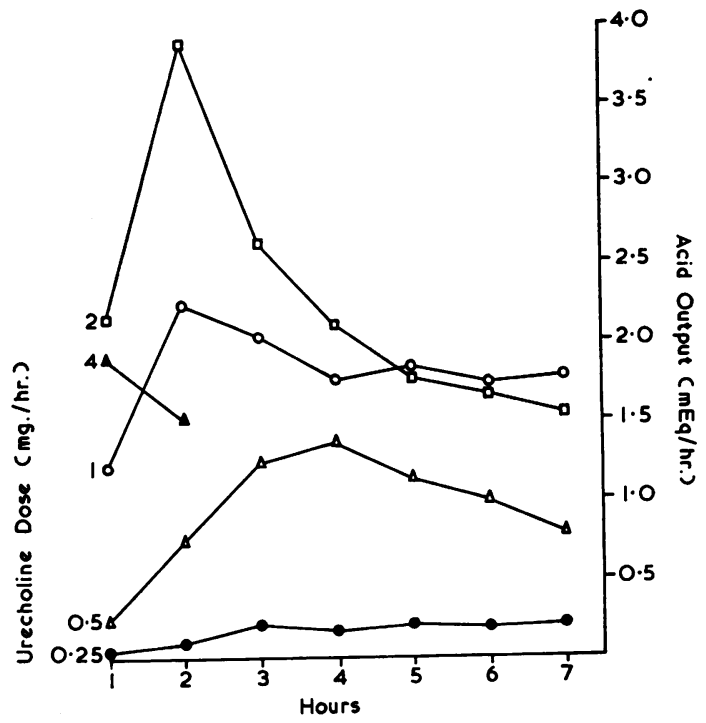

FIG. 1. Acid response of Heidenhain pouches to continuous intravenous injection of Urecholine at various constant dose rates. In this and subsequent figures, each point represents the mean value of tests on five dogs.

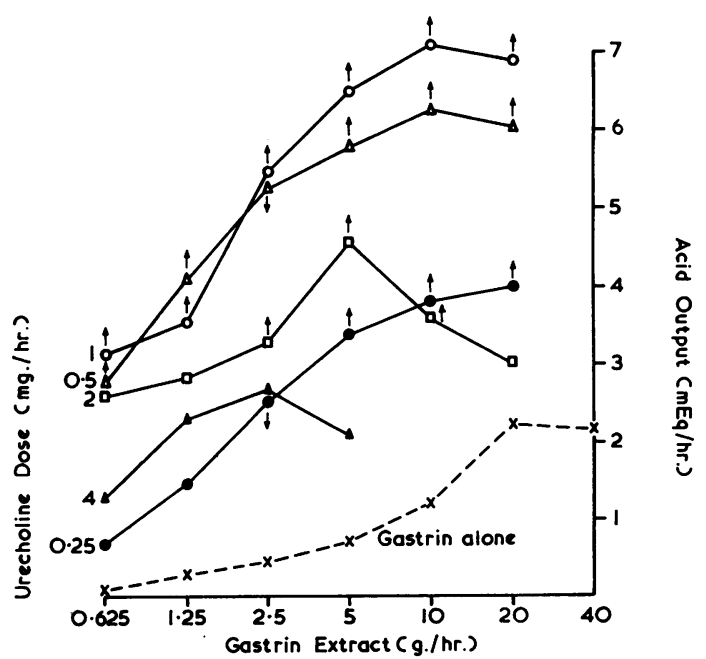

FIG. 2. Acid output of Heidenhain pouches in response to gastrin alone and to graded doses of gastrin superimposedon continuous injection of Urecholine at a constant rate. Points with an arrow projecting from them signify instances in which statistically significant $(p<0.05)$ potentiation occurred. 


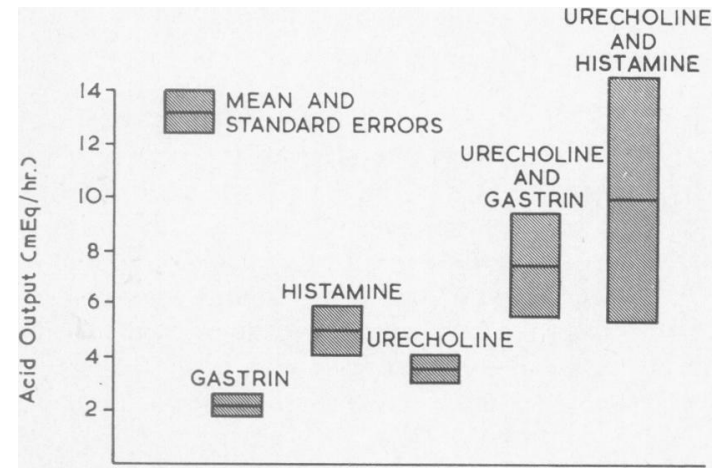

FIG. 3. Maximal acid responses of Heidenhain pouches to gastrin extract, histamine, and Urecholine, alone and in combination.

(2.2 mEq. per hour) or to Urecholine alone $(3 \cdot 6$ mEq. per hour). When given with Urecholine the dose of gastrin required for maximal response $(10 \mathrm{~g}$. per hour) was less than with gastrin alone $(20 \mathrm{~g}$. per hour).

URECHOLINE PLUS HISTAMINE The pattern obtained (Fig. 4) was similar in most respects to that of Urecholine plus gastrin. Clear evidence of potentiation was found with almost all combinations of Urecholine and histamine. At a dose of $2 \mathrm{mg}$. per hour Urecholine did not produce any greater acid

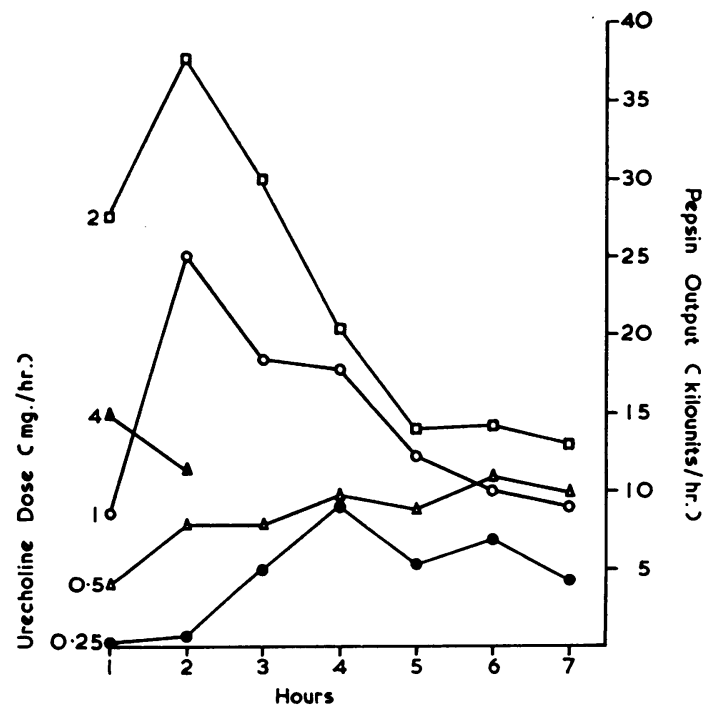

FIG. 5. Pepsin response of Heidenhain pouches to continuous intravenous injection of Urecholine at various constant dose rates. response in combination with histamine than it did at $1 \mathrm{mg}$. per hour. Thus, for both gastrin and histamine, $1 \mathrm{mg}$. per hour of Urecholine appears to be the optimal dose for potentiation.

The maximal acid response (Fig. 3) to combined administration of Urecholine and histamine $(9 \cdot 3$ $\mathrm{mEq}$. per hour) was significantly greater $(\mathrm{p}<0.01)$ than the maximum to histamine alone $(5 \cdot 3 \mathrm{mEq}$. per hour) or to Urecholine alone $(3.6 \mathrm{mEq}$. per hour). As with gastrin, histamine when acting with Urecholine gave maximal secretory rates with lower doses $(1 \mathrm{mg}$. dihydrochloride per hour) than did histamine alone (4 mg. dihydrochloride per hour).

\section{PEPSIN OUTPUTS}

Unlike the situation for acid secretion, in which each agent alone - gastrin, histamine, and Urecholine - can

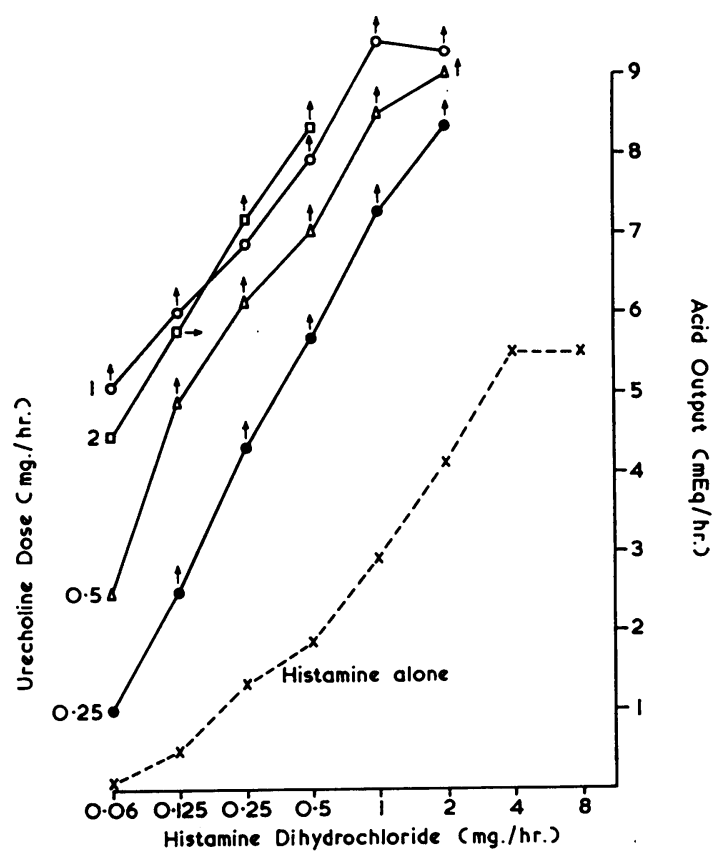

FIG. 4. Acid output of Heidenhain pouches in response to graded doses of histamine alone and to graded doses of histamine superimposed on continuous injection of Urecholine at a constant rate. Points with an arrow extending from them signify instances in which statistically significant $(p<0.05)$ potentiation occurred.

produce relatively high secretory rates, in the case of pepsin secretion only Urecholine is a potent stimulant when acting alone. Even the lowest dose rates of Urecholine used produced pepsin outputs of 


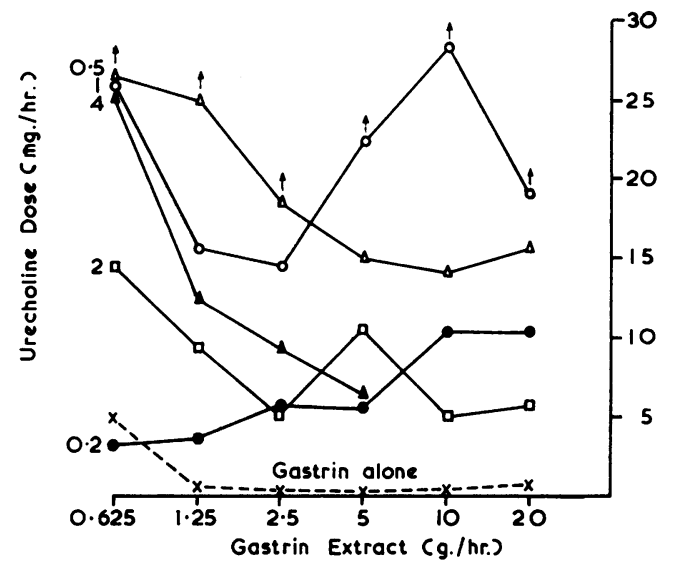

FIG. 6. Pepsin output of Heidenhain pouches in response to gastrin alone and to graded doses of gastrin superimposed on continuous injection of Urecholine at a constant rate. Points with an arrow projecting from them indicate instances in which statistically significant $(p<0.05)$ potentiation occurred.

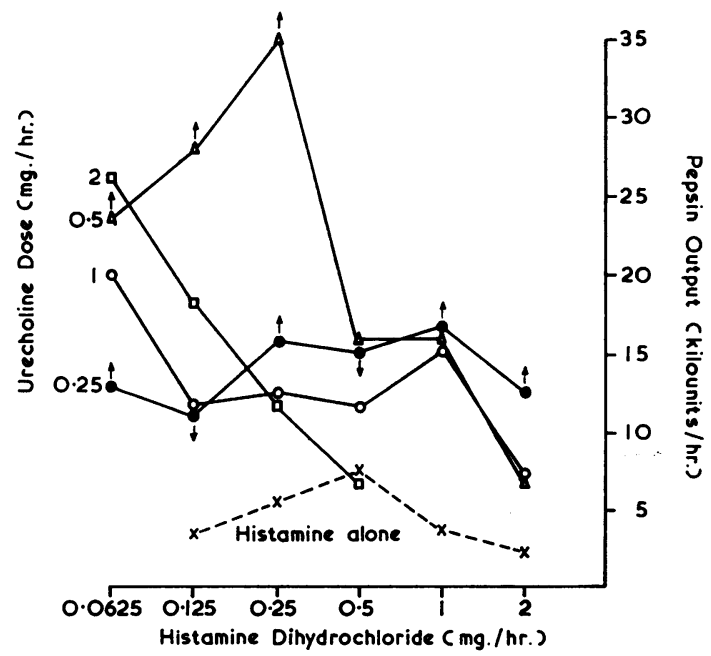

FIG. 7. Pepsin output of Heidenhain pouches in response to histamine alone and to graded doses of histamine superimposed upon continuous injection of Urecholine at a constant rate. Points with an arrow extending from them indicate instances in which statistically significant $(p<0.05)$ potentiation occurred. the same order as the maximum obtained to gastrin alone or to histamine alone.

URECHOLINE ALONE The time course of the pepsin responses to Urecholine alone (Fig. 5) were similar to those for acid (Fig. 1). With small doses a relatively steady rate was reached within two hours and then maintained for the remainder of the study. With larger doses, $1 \mathrm{mg}$. per hour and $2 \mathrm{mg}$. perhour, a peak was reached within two hours and was then followed by a sharp decrease with some tendency to stabilize at an intermediate level toward the end of the test. Because of these marked fluctuations in the time course of the pepsin responses, in testing for the occurrence of potentiation, the value for pepsin output to Urecholine alone that corresponded to the hour of the test under study was used.

URECHOLINE PLUS GASTRIN As shown in Fig. 6 the pepsin responses to gastrin alone were low. With combinations of Urecholine and gastrin, potentiation of pepsin response as judged by criterion 1 occurred in only a few instances, namely with $0.5 \mathrm{mg}$. Urecholine per hour plus $0.625,1.25$, and $2.5 \mathrm{~g}$. per hour of gastrin and with $1 \mathrm{mg}$. Urecholine per hour with 5,10 , and $20 \mathrm{~g}$. of gastrin per hour. With $2 \mathrm{mg}$. Urecholine per hour pepsin outputs with all doses of gastrin used were significantly lower $(p<0.05)$ than with this dose of Urecholine alone.

In no instance did a combination of doses of Urecholine and gastrin give higher maximal rates of secretion of pepsin than were produced with Urecholine alone.

URECHOLINE PLUS HISTAMINE Figure 7 shows that the pattern of pepsin response to the graded doses of histamine alone was an apparent increase in output with increasing doses at the lower dose rates followed by a decrease in output with increasing doses at the higher dose rates.

By criterion 1, potentiation of pepsin response occurred with 0.25 and $0.5 \mathrm{mg}$. Urecholine per hour plus most of the histamine doses used; maximal potentiation occurred with $0.5 \mathrm{mg}$. Urecholine per hour. With $1 \mathrm{mg}$. Urecholine per hour, and more particularly with $2 \mathrm{mg}$. Urecholine per hour, histamine doses higher than $0.625 \mathrm{mg}$. dihydrochloride depressed pepsin outputs to levels below those obtained with Urecholine alone $(p<0.05)$.

As with gastrin, in no instance did a combination of doses of Urecholine plus histamine give maximal rates of secretion of pepsin that were higher than those seen with Urecholine alone. In other words, with neither gastrin nor histamine was criterion 2 for potentiation of pepsin secretion ever fulfilled. This, of course, is in contrast with the situation for acid secretion. 


\section{DISCUSSION}

These studies clearly establish the existence of true potentiation between Urecholine and gastrin and between Urecholine and histamine in stimulation both of acid secretion and of pepsin secretion. Not all dose combinations resulted in potentiation; indeed, the highest dose rate of Urecholine used (4 mg. per hour) produced less stimulation when acting alone than did lower doses and also prevented any augmentation of response when gastrin was added to it. Gray and Ivy (1937) were the first to describe the dose reversal phenomenon for acetylcholine and stable choline esters in the stimulation of secretion of acid. They found that large doses produced less stimulation than small doses and that large doses also inhibited the secretion of acid stimulated by histamine, similar to the findings of the present study.

The pattern of potentiation with Urecholinegastrin differed from that with Urecholine-histamine. The dose of Urecholine required to produce maximal potentiation was more critical in the case of gastrin than of histamine. The maximal rate of acid secretion achieved with histamine stimulation was approximately the same with background doses of $0 \cdot 25,0.5,1$, and $2 \mathrm{mg}$. Urecholine per hour. By contrast, in the case of gastrin, maximal rates were higher with 0.5 and $1 \mathrm{mg}$. Urecholine per hour than with 0.25 or $2 \mathrm{mg}$. per hour.

Expressed as a percentage increase, the augmentation of maximal response produced by Urecholine was greater with gastrin (from 2.2 to $7.0 \mathrm{mEq}$. per hour, $218 \%$ increase) than with histamine (from 5.3 to $9.3 \mathrm{mEq}$. per hour, a $75 \%$ increase). The difference between the mean maximal rate for potentiated gastrin $(7.0 \mathrm{mEq}$. per hour) and for potentiated histamine $(9.3 \mathrm{mEq}$. per hour) is of doubtful statistical significance $(p<0 \cdot 1)$. In recent unpublished studies we have found that the maximal acid secretory responses to gastrin and to histamine are equal in dogs with gastric fistulas (vagally innervated). This suggests that the lower maximal response to gastrin than to histamine in Heidenhain pouches, as previously reported by Gillespie and Grossman (1963) and confirmed in the present study, is a result of the decrease in cholinergic tone produced by vagotomy. This also suggests that vagotomy reduces the response to gastrin more than to histamine, a supposition in keeping with the findings of the present study that Urecholine augments the gastrin response more than the histamine response. In other words, gastrin may be said to have a greater cholinergic dependency than histamine.

Is the degree of cholinergic tone that is provided by intact vagal innervation sufficient to produce maximal secretory responses to gastrin and histamine or would the addition of exogenous cholinergic action in the form of drugs elevate the maximum responses to these stimulants? Marks, Komarov, and Shay (1960) state that Mecholyl can increase the maximal secretory responses to gastrin and histamine in dogs with gastric fistulas but they do not give the data in support of this statement. By contrast, Payne and Kay (1962) found no increase in the maximal histamine response of the intact stomach in man by the addition of Mecholyl. If the results of both studies are confirmed, they might reflect a higher cholinergic tone normally present in the stomach of man as compared to that of dog. Obviously the question requires further study.

The pattern of pepsin responses was, by comparison with the acid responses, capricious. Few instances of potentiation were encountered, but when these did occur they were always in cases in which potentiation of acid secretion was also occurring. In some instances, e.g., with $2 \mathrm{mg}$. Urecholine per hour, the addition of gastrin or histamine to stimulation with Urecholine actually depressed pepsin secretion below the levels seen with Urecholine alone even though this same combination of agents produced potentiation of stimulation of acid secretion. No explanation for these results is readily apparent, but it might be noted that the dose reversal phenomenon for cholinomimetic agents applies to pepsin secretion as well as to acid secretion (Morton and Stravraky, 1949) and it is possible that at critical levels of Urecholine dosage the addition of gastrin or histamine causes reversal of effects on pepsin but not on acid secretion.

The importance of cooperation between neural and hormonal mechanisms in the regulation of gastric secretion is only beginning to be fully realized. When Uvnas (1942) first emphasized this relationship, little attention was paid to it. Now it pervades the whole fabric of gastric physiology. Problems in the effects of vagotomy, of ganglionic blocking and anticholinergic drugs, of cholinergic gastric reflexes recently described (Grossman, 1961, 1962), of variations in the responsiveness of the parietal cells, cannot be fully formulated without an appreciation of the several kinds of interaction between neural and hormonal effects.

\section{SUMMARY}

We studied secretion of acid and pepsin by Heidenhain pouches of dogs in response to a range of dose rates of Urecholine, gastrin extract, and histamine, given separately and in combination.

For most of the dose combinations of Urecholine 
plus gastrin and of Urecholine plus histamine acid secretory responses were greater than could be accounted for on the basis of the addition of stimulatory effects. Thus, true potentiation between these combinations of agents was demonstrated.

The maximal rates of acid secretion that could be attained with combinations of Urecholine plus gastrin or of Urecholine plus histamine were significantly higher than the maximal rates to any of the three agents acting singly. The degree of augmentation of maximal response by Urecholine was greater for gastrin than for histamine.

High dose rates of Urecholine (4 mg. per hour) not only did not potentiate the acid secretory response to gastrin but even failed to augment it.

Some dose combinations of Urecholine and gastrin and of Urecholine and histamine that produced potentiated acid responses also produced potentiated pepsin responses, but most did not, and some actually depressed pepsin secretion. Secretion of pepsin at maximal rates in excess of those attained with Urecholine alone did not occur with any combination of Urecholine plus gastrin or of Urecholine plus histamine.

Expert technical assistance was given by John Washington, Raymond Lichter, and Gerald Messick.
This work was supported in part by grant no. AM-03326 from the United States Public Health Service.

\section{REFERENCES}

Gaddum, J. H. (1959). Pharmacology, pp. 504 et seq. Ox ford University Press, London.

Gillespie, I. E., and Grossman, M. I. (1963). Inhibition of gastric secretion by extracts containing gastr $\mathrm{n}$. Gastroenterology, 44, 301-310.

Gray, J. S., and Ivy, A. C. (1937). Effects of Mecholyl on gastric secretion. Amer. J. Physiol., 120, 705-711.

Gregory, R. A., and Tracy, H. J. (1960). The preparation and properties of gastrin. J. Physiol. (Lond.), 156, 523-543.

Grossman, M. I. (1961). Stimulation of secretion of acid by distention of denervated fundic pouches in dogs. Gastroenterology, 41, 385-390.

- (1962). Secretion of acid and pepsin in response to distention of vagally innervated fundic gland area in dogs. Ibid., 42, 718-721.

- , and Marks, I. N. (1960). Secretion of pepsinogen by the pyloric glands of the dog, with some observations on the histology of the gastric mucosa. Ibid., 38, 343-352.

Marks, I. N., Komarov, S. A., and Shay, H. (1960). Maximal acid secretory response to histamine and its relation to parietal cell mass in the dog. Amer. J. Physiol., 199, 579-588.

Morton, G. M., and Stravraky, G. W. (1949). A histo-physiological study of the effect of intraarterial injection of acetylcholine upon the gastric mucosa of the dog. Gastroenterology, 12 , 808-820.

Payne, R. A., and Kay, A. W. (1962) The effect of vagotomy on the maximal acid secretory response to histamine in man. Clin. Sci., 22, 373-382.

Uvnas, B. (1942). The part played by the pyloric region in the cephalic phase of gastric secretion. Acta physiol. scand., 4, suppl., 13. 